Godard, Director of the École Monge in Paris, who has brought twenty of the pupils with him. M. Fau, Attorney-General of Algiers, is the President, and two papers are announced for to-day:-One by M. Robert, on the Humanitarian and Pedagogic Ideas of Jean Comimiac (1572-1670); the other by M. Berdellé, on the Employment of Colours as a Means of Retaining in the Mind certain given Numbers.

An excellent geological map of Algiers to the scale of I in 800,000 has recently been completed, and the formation of it has led to the simultaneous observation of various facts connected with the physical geography of the Central Sahara. A map of the proposed interior sea of the Sahara has also been prepared, and the Trans-Sahara Railway is spoken of as more than a probability. But we very much doubt if this can ever be a success. If it connected flourishing towns or portions of territory in which great cities are ever likely to be established, as in the case of the new American railways, there would be some hope for it. As it is, however over-populated the world may become, there is no likelihood of the formation of settlements in the heart of an unhealthy tropical region.

G. F. RODWELL

\section{MR. DARWIN ON VIVISECTION}

$\mathrm{H}$ ROM the Times we reproduce the following letter addressed by Mr. Darwin to Prof. Holmgren of Upsala, in answer to a request for an expression of his opinion on the question of the right to make experiments on living animals for scientific purposes-a question which is now being much discussed in Sweden :-

"Down, Beckenham, April 14, I88 I

"Dear Sir,-In answer to your courteous letter of April 7 I have no objection to express my opinion with respect to the right of experimenting on living animals. I use this latter expression as more correct and comprehensive than that of vivisection. You are at liberty to make any use of this letter which you may think fit, but if published I should wish the whole to appear. I have all my life been a strong advocate for humanity to animals, and have done what I could in my writings to enforce this duty. Several years ago, when the agitation against physiologists commenced in England, it was asserted that inhumanity was here practised and useless suffering caused to animals; and I was led to think that it might be advisable to have an Act of Parliament on the subject. I then took an active part in trying to get a Bill passed, such as would have removed all just cause of complaint, and at the same time have left physiologists free to pursue their researches-a Bill very different from the Act which has since been passed. It is right to add that the inves. tigation of the matter by a Royal Commission proved that the accusations made against our English physiologists were false. From all that I have heard however I fear that in some parts of Europe little regard is paid to the sufferings of animals, and if this be the case I should be glad to hear of legislation against inhumanity in any such country. On the other hand I know that physiology cannot possibly progress except by means of experiments on living animals, and I feel the deepest conviction that he who retards the progress of physiology commits a crime against mankind. Any one who remembers, as I can, the state of this science half a century ago must admit that it has made immense progress, and it is now progressing at an ever-increasing rate.

"What improvements in medical practice may be directly attributed to physiological research is a question which can be properly discussed only by those physiologists and medical practitioners who have studied the history of their subjects ; but, as far as I can learn, the benefits are already great. However this may be, no one, unless he is grossly ignorant of what science has done for mankind, can entertain any doubt of the incalculable benefits which will hereafter be derived from physiology, not only by man, but by the lower animals. Look, for instance, at Pasteur's results in modifying the germs of the most malignant diseases, from which, as it so happens, animals will in the first place receive more relief than man. Let it be remembered how many lives and what a fearful amount of suffering have been saved by the knowledge gained of parasitic worms through the experiments of Virchow and others on living animals. In the future every one will be astonished at the ingratitude shown, at least in England, to these benefactors of mankind. As for myself, permit me to assure you that I honour, and shall always honour, every one who advances the noble science of physiology.

$$
\text { "Dear sir, yours faithfully, }
$$

"To Prof. Holmgren"

\section{"Charles DaRWin}

\section{THE MAGNETIC SURVEY OF MISSOURI}

$\mathrm{I}$ the summer of 1878 the writer began a magnetic survey of the State of Missouri. The worik of the first summer was confined to the north-east part of the State, and no points of interest were brought out. During the summer of 1879 the work was extended over the western half of the State, and it was made apparent that diversity of surface exerted a much more important influence than had been suspected. The lines of equal declination were found to bend very sharply upon entering the large valleys, and the needle showed a tendency to set at right angles to the valleys. This tendency seemed to be greatest when the general direction of the valley made an angle of $45^{\circ}$ with the normal position of the needle, or roughly, when the valley runs north-east and south-west, or north-west and south-east. This tendency seems to be inappreciable when the valleys run north and south, or east and west.

In the report of 1878 (Trans. St. Louis Acad. of Sc., vol. iv. No. I, p. 143) it was suggested that this might result from the bending of the stream-lines of the earthcurrent sheet, due to the greater conducting power of the moist valleys. In order to settle this point, further examination is necessary, and it is proposed to determine the earth-currents at a number of properly selected stations.

During the summer of 1880 the work extended over the south-eastern part of the State, where still more important flexures of the isogonic lines were discovered. Here, however, the position of the needle is probably affected by the iron deposits, and the effect of contour is studied to less advantage. At the close of 1880 observations had been made at forty-five stations. In order to bring out the effect of contour, a relief map of the State was constructed in wax, and was finally reproduced in plaster. In this work use was made of the profiles of all the railroads in the State, together with a list of over 300 elevations in the State, collected by Gannett. The isogonic lines, which were first drawn upon an ordinary map, in the usual manner, to represent the observations thus far made, were then copied upon the relief map. In doing this it became apparent at once that the forty-five stations were wholly inadequate, and that the isogonic lines thus drawn are probably deserving of about the same weight that a topographical map would deserve if constructed from elevations at these stations.

The Chart is made after an artotype, which will accompany the third annual report in No. 2, vol. iv. Trans. St. Louis Academy of Science. In the original map the horizontal scale is twenty miles to the inch, the elevations being exaggerated 200 times. This exaggeration was necessary in order to bring out the form in the photograph, since on a relief map, i 50 feet square, the 